\title{
Increased efficiency of transfection of murine hybridoma cells with DNA by electropermeabilization *
}

\author{
Helga Stopper, Ulrich Zimmermann and Garry A. Neil * \\ Lehrstuhl für Biotechnologie, Universität Würzburg, Würzburg, F.R.G., and the Research Institute of Scripps Clinic, La Jolla, CA, U.S.A.
}

(Received 28 August 1987, revised received 23 November 1987, accepted 30 November 1987)

Dispase-treated murine hybridoma cells (SP2/0-Ag14) were transfected with the G418 resistance gene bearing plasmid pSV2-neo by electropermeabilization with a high degree of efficiency. The cells were subjected to intermittent multiple high-voltage short duration $(5 \mu \mathrm{s}) \mathrm{DC}$ pulses at intervals of $1 \mathrm{~min}$ in a weakly conducting medium followed by selection in G418-containing medium. The transfection medium, temperature, pulse duration, and voltage were empirically determined by preliminary electropermeabilization experiments. Increasing the number of pulses resulted in a higher percentage of transfected cells, but a decrease in the number of viable cells, with the optimal transfectant yield resulting when five pulses of 10 $\mathrm{kV} / \mathrm{cm}$ were administered. This method allows the rapid and efficient injection of DNA into mammalian cells, and permits the rapid production of stable, drug resistant hybridoma cell lines for use in subsequent fusion experiments.

Key words: DNA transfection; Electropermeabilization; Eukaryotic cell; Hybridoma; Drug resistance

\section{Introduction}

The injection of foreign DNA into eukaryotic cells, and its subsequent expression in these cells is a powerful research tool with wide application in cellular and molecular biology. Using this technique, it is possible to rapidly render otherwise susceptible cell lines resistant to antibiotics by injection and subsequent genomic integration and expression of bacterial antibiotic resistance genes. One important use for such drug resistant cells is the production of 'fusomas' or hybrid hybridomas (Milstein et al., 1983; Semenenko et al.; 1985,

Correspondence to: G.A. Neil, Ludwig Institute for Cancer Research, Toronto M4Y 1M4, Canada.

* This work was supported by grants from the BMFT, the DFLVR, the Deutsche Forschungsgemeinschaft (SFB 176), and the Medical Research Council of Canada.
Suresh et al., 1986) which may then be conveniently selected after somatir cell hybridization in appropriate antibiotic-containing medium (Lanzavecchia et al., 1987). A number of such drug resistance genes, incorporated in well characterized plasmid vectors are now readily available and functional in mammalian cells after integration.

We have recently refined and optimized the methodology for insertion of the plasmid vector containing the bacterial drug resistance gene, neomycin phosphotransferase (pSV2-neo) (Southern and Berg, 1982) into the non-secreting mammalian hybridoma cell line, SP2/0-Ag14 (Sp2/0) by means of electropermeabilization, thus enabling the selection of transfectants in growth medium supplemented with the antibiotic G418.

The crucial step in this method is the production of reversible electrical breakdown of the cell 
membrane, which is achieved when the cell is exposed to a field pulse of high intensity $(\mathrm{kV} / \mathrm{cm}$ range) and short duration (ns to $\mu \mathrm{s}$ range) (Zimmermann et al., 1974a,b; Zimmermann, 1986). When the total membrane potential exceeds a critical value of approximately $1 \mathrm{~V}$ at $20^{\circ} \mathrm{C}$ or 2 $\mathrm{V}$ at $4^{\circ} \mathrm{C}$ the membrane is transiently 'permeabilized' permitting the influx of DNA, proteins, or other substances into the cell (Zimmermann et al., 1976, 1981; Zimmermann, 1982; Stopper et al., $1985,1987)$. Longer duration and/or higher intensity pulses will result in irreversible electrical breakdown with consequent cell lysis (Zimmermann, 1982, 1986). The molecular events that follow electrical breakdown, culminating in membrane permeabilization are poorly understood and opinion remains divided regarding the possible formation of transient channels or 'pores' in the cell membrane as a consequence of electrical field application, i.e., so-called 'electroporation' (Neumann et al., 1982; Zimmermann, 1982; Sowers, 1985; Stopper et al., 1987). The presence of such channels alone could not account for the passage of whole cells through the cell membrane and it seems more likely that the application of the electrical field temporarily disrupts the orderly arrangement of the phospholipid bilayer and other membrane components, i.e., permeabilization of the membrane in areas where the field strength is sufficiently high (Zimmermann, 1983). Nevertheless, existing knowledge permits cogent manipulation of the process such that a variety of substances may be introduced into many cell types (Auer et al., 1976; Zimmermann and Pilwat, 1976; Zimmermann et al., 1980; Schussler and Ruhenstroth-Bauer, 1984).

We have previously shown that this method may be used for the transfection of yeast (Broda et al., 1987) and murine fibroblasts (Stopper et al., 1975; Zimmermann et al., 1976), with an efficiency greater than that reported for chemical transfection methods (Graham and Van der Eb, 1973; Pellicer et al., 1980; Berman et al., 1984). In the experiments reported here, high numbers of stable transformants were obtained in the presence of very low plasmid concentrations by electroinjection using a series of 5-10 pulses with the cell suspension maintained at $4^{\circ} \mathrm{C}$, each pulse being administered at intervals of $1 \mathrm{~min}$. This delay is required to allow sufficient resealing of the electropermeabilized cell membrane such that the cumulative toxicity of multiple pulsations does not result in excessive cell death. With some modifications, this method was used to efficiently generate large numbers of stable G418 resistant murine hybridoma cells, SP2/0.

\section{Materials and methods}

The non-secreting murine hybridoma cell line, SP2/0 (SP2/0-Ag14) was obtained from ATCC (Bethesda, MD) and cultured in complete growth medium (CGM) as follows: RPMI 1640 (Boehringer, Mannheim) supplemented with L-glutamine $2 \mathrm{mM}$ (Boehringer, Mannheim), 10\% fetal bovine serum (Boehringer, Mannheim), and $5 \times$ $10^{-5} \mathrm{M} 2$-mercaptoethanol. The cells were grown at $37^{\circ} \mathrm{C}$ in an incubator supplemented with $5 \%$ $\mathrm{CO}_{2}$. A subclone of these cells chosen for the subsequent experiments was found to die rapidly in G418 (Gibco, Grand Island, NY) supplemented medium at concentrations of less than $100 \mu \mathrm{g} / \mathrm{ml}$. Cells were harvested in $\log$ growth phase at concentrations of $3 \times 10^{5} / \mathrm{ml}$ and incubated for $1 \mathrm{~h}$ in complete growth medium supplemented with dispase (grade I) $0.1 \mathrm{mg} / \mathrm{ml}$ (Boehringer, Mannheim). The cells were then washed once in chilled $\left(4^{\circ} \mathrm{C}\right) \mathrm{CGM}$ followed by $1-2$ washes in pulse medium, the composition of which is as follows: inositol (Serva, Heidelberg) $0.22 \mathrm{M}, \mathrm{KCl} 30 \mathrm{mM}$, $\mathrm{KH}_{2} \mathrm{PO}_{4} / \mathrm{K}_{2} \mathrm{HPO}_{4} 1.1 \mathrm{mM}, \mathrm{pH} 7.2$ then resuspended in pulse medium at a final concentration of $0.5-1.0 \times 10^{6} / \mathrm{ml}$.

The plasmid pSV2-neo was linearized by digesting a $50 \mu \mathrm{g}$ aliquot for $3 \mathrm{~h}$ at $37^{\circ} \mathrm{C}$ with $3 \times 50 \mathrm{U}$ of $E c o$ RI (BRL, Bethesda, MD) added at 0,1 and $2 \mathrm{~h}$. The linearized plasmid was added to the final cell suspension at a concentration of $1.0 \mu \mathrm{g} / \mathrm{ml}$ excepting those experiments which were performed in the absence of plasmid DNA to serve as controls. $1.2 \mathrm{ml}$ of the cell suspension was then loaded into the chamber of a high voltage electric discharge apparatus which was maintained at $4^{\circ} \mathrm{C}$.

In brief, the apparatus used consists of two flat stainless steel electrodes mounted in parallel in a plexiglass chamber at a distance of $3.3 \mathrm{~mm}$ and cooled by a Peltier element. The total volume of 
the chamber is $1.2 \mathrm{ml}$. The chamber is connected to a capacitor by a switch, which is, in turn, connected to a voltage generator. When the switch is closed, the capacitor is discharged exponentially (Zimmermann, 1983).

A varying number $(0-10)$ of short duration, high voltage pulses $(10 \mathrm{kV} / \mathrm{cm}$ for $5 \mu \mathrm{s})$ were then applied at intervals of $1 \mathrm{~min}$. After pulsing, the cells were gently flushed from the pulse chamber and transferred into warm phenol-free RPMI 1640 medium (Biochrom, Berlin) and allowed to 'reseal' for $10 \mathrm{~min}$ at $37^{\circ} \mathrm{C}$. The cells were then washed and resuspended in CGM, examined microscopically, counted and distributed into the wells of 24-well culture plates (Greiner, Nurtingen) at a concentration of $10^{4} / \mathrm{ml}$. Each well of these plates is marked by a raised $4 \times 4$ grid to prevent 'crosscontamination' of G418-resistant colonies and to facilitate recording of colony numbers. Numbers of viable cells were determined by microscopical examination using a phase contrast microscope and cell counts were determined using a hemocytometer.

$48 \mathrm{~h}$ after pulsing, G418-supplemented CGM was added such that the final concentration of G418 was $250 \mu \mathrm{g} / \mathrm{ml}$. In preliminary experiments, this dose was determined to inhibit the growth of non-transfected SP2/0-Ag14 cells, while minimally inhibiting the growth of transfected cells. The culture medium was changed twice weekly thereafter with the same dose of G418 being maintained. After 12 days the plates were examined with an inverted phase-contrast microscope and the number of viable colonies were counted and the efficiency of transfection, i.e., the percent viable G418-resistant colonies obtained were calculated. Some of these colonies were grown for a longer period in G418 (more than 28 days) and continued to exhibit $\mathrm{G} 418$ resistance.

\section{Results}

The number of cells surviving pulsing and the percent of resulting stable G418-resistant colonies from a representative set of experiments are given in Table I. With the voltage and pulse duration held constant at $10 \mathrm{kV} / \mathrm{cm}$ and $5 \mu \mathrm{s}$, respectively, it will be seen that as the number of pulses administered increases, the number of cells surviving immediately after pulsation diminishes, while the percent of stable G418-resistant cells (as a function of the number of surviving cells) rises (Fig. 1). The absolute number of resistant colonies diminishes beyond five pulses, however, owing to the smaller number of surviving cells (Fig. 2).

There was some interexperimental variation in the optimal yield of resistant clones (varying from 0.4 to $4.8 \%$ in a total of five experiments) depending upon the condition of the cells at the time of

TABLE I

RESULTS OF A TYPICAL TRANSFECTION EXPERIMENT

\begin{tabular}{lllllll}
\hline $\begin{array}{l}\text { Number } \\
\text { of } \\
\text { pulses }\end{array}$ & $\begin{array}{l}\text { Plasmid } \\
\text { added }\end{array}$ & $\begin{array}{l}\text { Cells } \\
\text { before } \\
\text { pulsing } \\
\left(\times 10^{5}\right)\end{array}$ & $\begin{array}{l}\text { Cells } \\
\text { after } \\
\text { pulsing } \\
\left(\times 10^{5}\right)\end{array}$ & $\begin{array}{l}\text { \% Surviving } \\
\text { cells } \\
\text { post-pulse }\end{array}$ & $\begin{array}{l}\text { Number of } \\
\text { G418- } \\
\text { resistant } \\
\text { colonies }\end{array}$ & $\begin{array}{l}\text { \% G418- } \\
\text { resistant } \\
\text { colonies }\end{array}$ \\
\hline 0 & & 9.0 & 8.8 & 97.8 & 0 & 0 \\
3 & - & 9.0 & 7.5 & 83.3 & 36 & 0.005 \\
0 & - & 6.4 & 4.1 & 64.1 & 96 & 0.023 \\
1 & + & 6.0 & 3.7 & 61.6 & 401 & 0.11 \\
2 & + & 6.0 & 2.8 & 47.0 & 677 & 0.24 \\
3 & + & 6.0 & 2.2 & 36.6 & 658 & 0.30 \\
5 & + & 6.0 & 1.5 & 25.0 & 766 & 0.51 \\
10 & + & 6.0 & 0.6 & 10 & 474 & 0.79 \\
\hline
\end{tabular}

a Total number of viable cells (as determined by phase contrast microscopy) flushed from the pulse chamber after administration of the indicated number of pulses.

b Number of colonies of SP2/0-Ag14 cells observed after 12 days of culture in CGM supplemented with G418.

c G418-resistant colonies/total viable cells post-pulse administration (a) $\times 100$. 


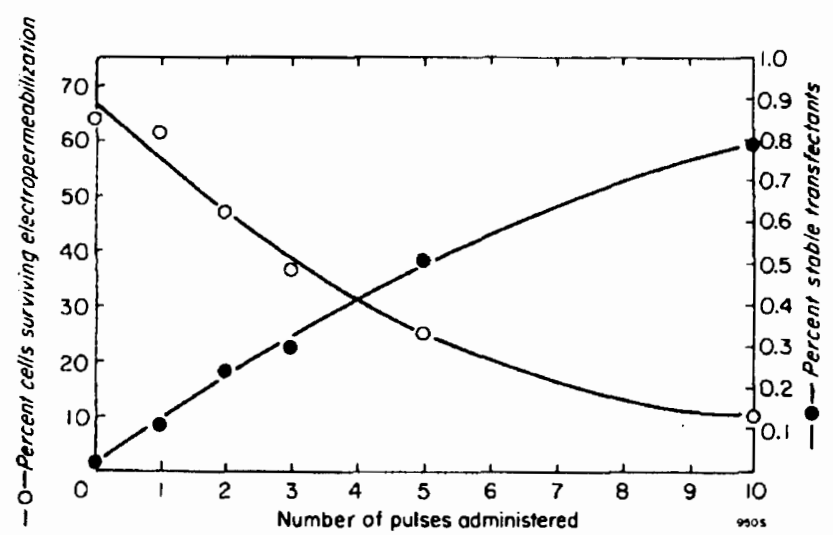

Fig. 1. Percent of cells surviving electropermeabilization as determined by microscopical examination immediately following application of varying numbers of $10 \mathrm{kV} / \mathrm{cm}$ pulses, and percent stable G418-resistant transfectants obtained after selection in G418-supplemented CGM (as a percentage of surviving cells initially cultured).

experimentation. The percentage of stable transfectants was several orders of magnitude higher in these experiments than that generated by calcium phosphate coprecipitation controls (data not shown).

The administration of five pulses proved to be consistently optimal with cell viabilities varying from $8 \%$ to $25 \%$, with an average of $15 \%$. The administration of ten pulses always resulted in lower cell survival (averaging 11\%).

The number of cells that took up the plasmid without subsequent integration was not determined in these experiments. It is presumed that

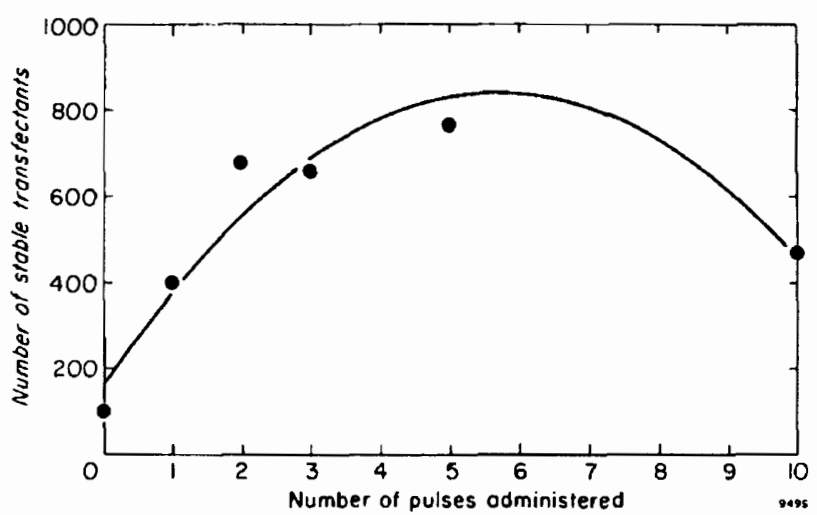

Fig. 2. Absolute numbers of stable G418-resistant colonies selected in CGM supplemented with G418 in a typical experiment after the application of varying numbers of $10 \mathrm{kV} / \mathrm{cm}$ pulses. The optimal number of colonies (766) were obtained when five pulses were administered. some of the cells bearing nonintegrated pSV2-neo are able to temporarily survive in G418 due to the transient synthesis of neomycin phosphotransferase. However, for most purposes, only those cells which are truly resistant to the selecting drug, i.e., stable transfectants are of interest. It is likely that cells exhibiting active growth in high concentrations of $\mathrm{G} 418$ beyond 12 days post transfection had integrated the plasmid into their genome and were therefore resistant.

It is possible that higher transfection efficiencies might have resulted if higher concentrations of plasmid were used but the addition carrier DNA did not increase the efficiency of transfection in preliminary experiments (data not shown). However, those cells undergoing sham transfection in the presence of plasmid DNA had a much lower survival as compared with those cells undergoing sham transfection in the absence of plasmid DNA (Table I) suggested that increasing the DNA concentration may have had deleterious consequences.

A small number of G418-resistant clones were consistently found in the experiments wherein pulses were applied in the absence of plasmid DNA (Table I). This occurred much less frequently in the control groups that were not pulsed, although it was seen when plasmid was added to cell suspensions that were sham pulsed. This latter observation is explained by the spontaneous transfer of plasmid across the cell membrane. The increased frequency of G418 resistant cells after pulsing in the absence of plasmid may be the result of an increased frequency of mutation induced by electrical field interactions with DNA, although there is no experimental evidence to support this to date.

\section{Discussion}

A number of methods for DNA transfection of a variety of mammalian cell lines have been previously described including the use of DEAE dextran (McCutchan and Pagano, 1968), calcium phosphate coprecipitation (Graham and Van der $\mathrm{Eb}, 1973$ ), direct transfer by bacterial protoplast fusion (Schaffner, 1980), microinjection (Yamamoto et al., 1982), liposome mediated transfer 
(Schaeffer-Ridder et al., 1982), retroviral vectors (Gruber et al., 1985), laser-mediated transfer (Kurata et al., 1986) and electroinjection methods (Zimmermann, 1974a). Most of these methods were developed for use with adherent cells in monolayer culture and their efficiency is markedly reduced when they are applied to lymphoid cells is suspension (Rice and Baltimore, 1982; Oi et al., 1983). Some of the more exotic techniques requiring lasers, liposomes or microinjection apparatus are technically demanding and have not enjoyed wide application, while retroviral transfer requires extensive DNA manipulation.

The electropermeabilization method which was first introduced more than 12 years ago by Zimmermann and coworkers (1974a,b) has been consistently more efficient than chemical methods for the transfection of mammalian cells, is reproducible and is technically easy. Previous applications of this method required relatively high concentrations of DNA (Pellicer et al., 1980; Zimmermann, 1986), have produced suboptimal efficiencies of stable transfectants (Pellicer et al., 1980; Toneguzzo et al., 1986) and have not been reported to be successful for the transfection of hybridomas. The results reported here demonstrate that when appropriate pulse medium, temperature and field conditions are maintained, the electropermeabilization method may be used to derive large numbers of stable transfected hybridoma cells for use in subsequent experiments, and that relatively small amounts of DNA may be used.

The electrolyte concentration of the pulse medium is of particular importance. The addition of $\mathrm{KCl} 30 \mathrm{mM}$ facilitates an asymmetrical breakdown of the cell membrane, such that electropermeabilization of only one 'hemisphere' of the pulsed cells results (Zimmermann and Stopper, 1987). Thus, the restoration of the original membrane impermeability following breakdown is greatly enhanced, and this is especially so at low temperatures. In this manner, cell survival increases greatly, without compromising entry of DNA.

The application of pulses in an iterative fashion with sufficient interval time for membrane recovery $(1 \mathrm{~min})$ to occur, while maintaining the cells at $4^{\circ} \mathrm{C}$ is key to obtaining optimum yields.
Several pulses of slightly supercritical field strength are required in order to permeabilize sufficiently large areas of membrane to allow entry of plasmid DNA owing to the angular dependence of the breakdown voltage (Zimmermann et al., 1974a, 1980). Multiple pulse application in this fashion is best performed with relatively long interval times between consecutive pulses since Brownian motion and cell rotation will allow exposure of different cell membrane areas to electropermeabilization, increasing efficiency of transfection, while reducing cell injury.

Moreover, without sufficient time for resealing to occur between pulses, there would not be an adequate increment in the cell membrane potential in response to subsequent pulses. This would result in the flux of current through the still permeabilized area of the membrane, injuring the cell.

Maintenance of the cell suspension at relatively low temperature allows maximal duration of the permeabilized membranes areas after pulsing. This facilitates the entry of DNA into the cell, while diminishing premature cell resealing.

It should be noted that the best growth conditions for particular cell lines selected for transfection, as well as the optimal concentration of the selecting drug must be carefully chosen if the maximum number of transfected clones are to be obtained while minimizing the number of cells lost to nonspecific toxicity, and inhibiting the growth of non-transfected cells. This is usually best accomplished by using cells in log growth phase, and by performing a preliminary experiment wherein the lowest concentration of selecting drug that inhibits the growth of the cell line is determined.

It will be seen that the optimal number of resistant colonies is obtained when five pulses are administered (Fig. 2). It will be noted that a small number of resistant colonies were found after sham electroinjection when the cells are suspended in the presence of plasmid, but the number of transfectants is, of course, low. A small number of resistant colonies were also found in the multiple pulse sham transfection, even though no plasmid was present in the chamber. This might have been the result of the appearance of spontaneous mutants resistant to G418. The fact that fewer or 
no G418-resistant cells were found among those cells which were not pulsed, and had no exposure to plasmid suggests that electric field interactions with DNA may cause an increased mutation frequency,

The addition of plasmid to the final cell suspension consistently resulted in a somewhat greater cell loss even when pulses are omitted. This might be a result of the general increased 'cell stickiness' that results when DNA is present in the cell suspension. The cell clumping that results may lead to increased cell susceptibility to electrical pulse toxicity. Alternatively, the presence of higher amounts DNA on the cell surface may render the cells more susceptible to electrical field toxicity or increase the likelihood of DNA integration into sites which are not compatible with survival. We have previously noted that the use of higher concentrations of DNA resulted in reduced yields of murine fibroblasts (Stopper et al., 1985).

As previously noted by our group (Stopper et al., 1985) and others (Pellicer et al., 1980) the use of linearized DNA is several fold more efficient than circular, i.e., 'native' plasmid DNA. This might be due to increased efficiency of DNA injection, integration or both. Our results would indicate that the use of carrier DNA is not mandatory when $\mu \mathrm{g} / \mathrm{ml}$ quantities of plasmid DNA are available.

From the foregoing discussion, it is clear that one must carefully consider the interaction of the various parameters which come into play during the process of electroinjection, if one hopes to obtain high efficiency yields. The lower transfection efficiencies reported by other authors using various electroinjection protocols (Potter et al., 1984; Toneguzzo et al., 1986) may in part be attributed to lack of attention to one or more of the aforementioned considerations. Only Chu et al. (1987) have reported stable transfection rates as high as $1 \%$, but this was achieved in a variety of adherent monolayer cells by applying very long duration pulses $(7 \mathrm{~ms})$ of relatively low voltage and using DNA concentrations of $20 \mu \mathrm{g} / \mathrm{ml}$ with $500 \mu \mathrm{g} / \mathrm{ml}$ carrier DNA. Such long pulse durations would be expected to result in irreversible membrane breakdown and to result in the death of many otherwise viable cells. The fact that many of the transfectants derived from these experi- ments survived only transiently in the selection medium may suggest that they sustained injury which was ultimately lethal.

With appropriate application of the method described here, we believe that it should be possible to efficiently obtain large numbers of stable transfected mammalian cell clones to be used in subsequent fusion experiments or for other purposes, even when comparatively small numbers of cells and small amounts of DNA are available, and possibly where other methods have failed.

\section{Acknowledgements}

The authors gratefully acknowledge the criticism and suggestions of Norman R. Klinman, M.D., Ph.D., Research Institute of Scripps Clinic, La Jolla, CA, David Sammons, Ph.D., University of Arizona, Tuscon, AZ and Howard B. Urnovitz, Ph.D., Medical Research Institute, San Francisco, CA.

\section{References}

Auer, D., Brandner, G. and Bodemer, W. (1976) Dielectric breakdown of the red blood cell membrane and uptake of SV40 DNA and mammalian cell RNA. Naturwissenschaften 63,391 .

Berman, J.W., Basch, R.S. and Pellicer, A. (1984) Gene transfer in lymphoid cells: expression of the Thy-1.2 antigen by Thy-1.1 BW5147 lymphoma cells transfected with unfractionated cellular DNA. Proc. Natl. Acad. Sci. U.S.A. 81, 7176.

Broda, H.G., Schnettler, R. and Zimmermann, U. (1987) Parameters controlling yeast hybrid yield in electrofusion: the relevance of pre-incubation and the skewness of the size distributions of both fusion partners. Biochim. Biophys Acta 899, 25.

Chu, G., Hayakawa, H. and Berg, P. (1987) Electroporation for the efficient transfection of mammalian cells with DNA. Nucleic Acids Res. 15, 1311.

Graham, F.L. and Van der Eb, A.J. (1973) A new technique for the assay of infectivity of human adenovirus 5 DNA. Virology 52, 456.

Gruber, H.E., Finley, K.D., Hershberg, R.M., Katzman, S.S., Laikind, P.K., Seegmiller, J.E., Friedman, T., Yee, J.K. and Jolly, D.J. (1985) Retroviral vector-mediated gene transfer into human hematopoietic progenitor cells. Science 230, 1057.

Kurata, S., Tsukakoshi, M., Kasuyu, T. and Ikawa, Y. (1986) The laser method for efficient introduction of foreign DNA into cultured cells. Exp. Cell. Res. 162, 372. 
Lanzavecchia, A. and Scheidegger, D. (1987) The use of hybrid hybridomas to target human cytotoxic T lymphocytes. Eur. J. Immunol. 17, 105.

McCutchan, J.H. and Pagano, J.S. (1968) Enhancement of the infectivity of simian virus $\mathbf{4 0}$ deoxyribonucleic acid with diethylamino-dextran. J. Natl. Cancer Inst. 41, 351.

Milstein, C. and Cuello, A.C. (1983) Hybrid hybridomas and their use in immunochemistry. Nature 305, 537.

Neumann, E., Schaeffer-Ritter, M., Wang, Y., and Hofschneider, P.H. (1982) Gene transfer into mouse lyoma cells by electroporation in high electric fields. EMBO J. 1, 841.

Oi, V.T., Morrison, S.L., Herzenberg, L.A. and Berg, P. (1983) Immunoglobulin gene expression in transformed lymphoid cells. Proc. Natl. Acad. Sci. U.S.A. 80, 825.

Pellicer, A., Robins, B., World, R., Sweet, J., Jackson, J., Lowry, I., Roberts, J.M., Sim, G.K., Silverstein, S. and Axel, R. (1980) Altering genotype and phenotype by DNA-mediated gene transfer. Science 209, 1414.

Potter, H., Weir, L. and Leder, P. (1984) Enhancer-dependent expression of human kappa immunoglobulin genes introduced into mouse pre-B lymphocytes by electroporation. Proc. Natl. Acad. Sci. U.S.A. 81, 7161.

Rice, D. and Baltimore, D. (1982) Regulated expression of an immunoglobulin gene introduced into a mouse lymphoid cell line. Proc. Natl. Acad. Sci. U.S.A. 79, 7862.

Schaeffer-Ridder, M., Wang, Y. and Hofschneider, P.H. (1982) Liposomes as gene carriers: efficient transformation of mouse L-cells by the thymidine kinase gene. Science 215 , 166.

Schaffner, W. (1980) Direct transfer of cloned genes from bacteria to mammalian cells. Proc. Natl. Acad. Sci. U.S.A. $77,2163$.

Schussler, W. and Ruhenstroth-Bauer, G. (1984) Stomatocytosis of latex particles ( 0.26 micron) by rat erythrocytes by the electrical breakdown technique. Blut 49, 213.

Semenenko, F.M., Bramwell, S., Sidebottom, E. and Cuello, A.C. (1985) Development of a mouse antiperoxidase secreting hybridoma for use in the production of a mouse PAP complex for immunocytochemistry and as a parent cell line in the development of hybrid hybridomas. Histochemistry 83, 405.

Southern, P.J. and Berg, P. (1982) Transformation of mammalian cells to antibiotic resistance with a bacterial gene under control of the SV40 early region promoter. J. Mol. Appl. Genet. 1, 327.

Sowers, A.E. (1985) Movement of a fluorescent lipid label from a labeled erythrocyte membrane to an unlabeled erythrocyte membrane following electric-field-induced fusion. Biophys. J. 47, 171a.

Stopper, H., Zimmermann, U. and Wecker, E. (1985) High yields of DNA-transfer into mouse L-cells by electropermeabilization. Z. Naturforsch. 40c, 929.

Stopper, H., Jones, H. and Zimmermann, U. (1987) Large scale transfection of mouse $\mathrm{L}$-cells by electropermeabilization. Biochim. Biophys. Acta 900, 38.

Suresh, M.R., Cuello, A.C. and Milstein, C. (1986) Bispecific monoclonal antibodies from hybrid hybridomas. Methods Enzymol. 121, 210.

Toneguzzo, F., Hayday, A.C. and Keating, A. (1986) Electric field-mediated DNA transfer: transient and stable gene expression in human and mouse lymphoid cells. Mol. Cell. Biol. 6, 703.

Yamamoto, F., Furusawa, M., Furusawa, I. and Obinata, M. (1982) A new efficient technique for mechanically introducing foreign DNA into the nuclei of culture cells. Exp. Cell. Res. 142, 79.

Zerbib, D., Amalric, F. and Teissie, J. (1985) Electric field mediated transformation: isolation and characterization of a $\mathrm{TK}^{+}$subclone. Biochem. Biophys. Res. Commun. 129, 611.

Zimmermann, U. (1982) Electric field-mediated fusion and related electrical phenomena. Biochim. Biophys. Acta 694, 227.

Zimmermann, U. (1983) Electrofusion of cells: principals and industrial potentials. Trends Biotechnol. 1, 149.

Zimmermann, U. (1986) Electrical breakdown, electropermeabilization and electrofusion. Rev. Physiol. Biochem. Pharmacol. 105, 175.

Zimmermann, U. and Pilwat, G. (1976) Organ specific application of drugs by means of cellular capsule systems. $Z$. Naturforsch. 31c, 732.

Zimmermann, U. and Stopper, H. (1987) Electrofusion and electropermeabilization of cells. In: E. Bertoli, D. Chapman, A. Cambria and U. Scapagnini (Eds.), Fidia Research Series, Vol. 7. Liviana Press, Padua, p. 371.

Zimmermann, U., Pilwat, G. and Riemann, F. (1974a) Reversible dielectric breakdown of cell membranes by electrostatic fields. Z. Naturforsch. 29c, 304.

Zimmermann, U., Pilwat, G. and Riemann, F. (1974b) German Patent no. 2405119, U.S. Patent no. 4154668.

Zimmermann, U., Riemann, F. and Pilwat, G. (1976) Enzyme loading of electrically homogeneous human red blood cell ghosts prepared by dielectric breakdown. Biochim. Biophys. Acta 436, 460.

Zimmermann, U., Pilwat, G. and Vienken, J. (1980) Erythrocytes and lymphocytes as drug carrier systems: techniques for entrapment of drugs in living cells. Recent Results Cancer Res. 75, 2521.

Zimmermann, U., Scheurich, G., Pilwat, G. and Benz, R. (1981) Angew. Chem. Int. Ed. 20, 325. 